\title{
ENSINO DE JORNALISMO E DESENVOLVIMENTO DA ESCRITA: INFLUÊNCIA DA ORGANIZAÇÃO TÓPICA DA ENTREVISTA NA ELABORAÇÃO DE PERFIS
}

\author{
Journalism education and the development of writing: the influence of topical \\ organization of interviews in the construction of profiles
}

\begin{abstract}
Enseñanza de periodismo y desarollo de la escrita: influenciación de la organización topica de la entrevista em la elaboración de perfiles
\end{abstract}

Agnes Francine de Carvalho

Mariano

Professora da Universidade Federal de Ouro Preto (UFOP)

agnesmariano@gmail.com

\section{Resumo}

Neste trabalho iremos analisar o modo como a entrevista (oral) participou da elaboração de perfis (escrita) na produção de estudantes de jornalismo. A intenção é observar a interação fala-escrita em processos de desenvolvimento da escrita que envolvem retextualização (passagem do oral para o escrito). Para identificar essa interação, usaremos a ideia de tópico (tema), que nos mostra em que momentos a sequência dos tópicos da entrevista foi mantida ou alterada no perfil. Também buscaremos identificar as diferentes soluções exploradas pelos estudantes e a relação dessas soluções com a maturidade da sua escrita. E, assim, localizar opções didáticas aplicáveis em cursos de jornalismo que sejam compatíveis com esse quadro.

Palavras-chave: Ensino de jornalismo. Perfil. Entrevista.

\begin{abstract}
This paper analyzes how interviews (oral) participate in the construction of profiles in the work of Journalism students. The objective was to observe the interaction between speech and writing in processes of writing development that involve retextualization (transition from oral to writing). In order to identify this interaction, we have used the idea of topic (theme). It indicated the moments where the sequence of the interview's topical segments was maintained or changed. We aimed to identify the different solutions used by the students and the relation with the maturity of their writing. The research showed the following trend: the less the maturity of writing, the more the loyalty to the interview's topical organization. The more the maturity of writing, the greater the use of global planning, which pointed to topic reorganization. This conclusion led us to identify educative options applicable to Journalism courses.
\end{abstract}

Key words: Journalism education. Profile. Interview. 


\section{Resumen}

En este trabajo vamos analizar la maniera como la entrevista (oral) participó de la elaboración de perfiles (escrita) en la producción de estudiantes de periodismo. La intención es observar la interacción habla-escrita en el proceso de desarrollo de la escrita que involucra retextualización (pasaje del oral para lo escrito). Para identificar esa interacción, usaremos la idea de tópico (tema), que nos enseña en que momento la secuencia de los tópicos de la entrevista fue mantenida o alterada en el perfil. También buscaremos identificar las diferentes soluciones exploradas por los estudiantes y la relación de esas soluciones con la madurez de su escrita. Y, así, ubicar opciones didácticas aplicables en cursos de periodismo que sean compatibles con ese cuadro.

Palabras clave: Enseñanza de periodismo. Perfil. Entrevista.

\section{INTRODUÇÃO}

Esta investigação se insere nos estudos sobre jornalismo e educação, mais especificamente, nas investigações sobre a aprendizagem da escrita no ensino de jornalismo. Os gêneros que serão aqui estudados são a entrevista (oral) e o perfil (escrito). Perfil, em jornalismo, é o gênero que conta uma história de vida. Ou que conta trechos de uma vida, ou até um aspecto dela. Mas o central é: trata-se de um texto que tem como foco a vida de uma única pessoa (SODRÉ, 1986). Em relação à entrevista, o que nos interessa é entender as potencialidades exploradas por estudantes de jornalismo ao partirem da entrevista - e especialmente da entrevista sobre história de vida - para a produção do texto escrito. Já o perfil foi escolhido por suas características facilitadoras e motivadoras. No jornalismo, na produção da maioria dos gêneros parte-se do oral (a fala) para a construção do texto (o escrito). E geralmente parte-se também de uma forma de interação oral face a face (a entrevista). Interação que é potencializada quando trata-se de determinados temas. Um deles certamente é a história de vida, que envolve emoções, empatia e, assim, motivações.

A história de vida, no jornalismo e em qualquer outro campo, exerce sempre um importante papel de abertura ao outro e, assim, de construção de diálogo (MEDINA, 1995) e relações mais solidárias. Pois esse tema é indissociável da empatia, capaz de mobilizar escreventes e leitores:

Os perfis cumprem um papel importante que é exatamente gerar empatias. Empatia é a preocupação com a experiência do outro, a tendência a tentar sentir o que sentiria se estivesse nas mesmas situações e circunstâncias experimentadas pelo personagem. Significa compartilhar as alegrias e 
tristezas de seu semelhante, imaginar situações do ponto de vista do interlocutor. Acredito que a empatia também facilita o autoconhecimento (de quem escreve e de quem lê) (VILAS BOAS, 2003, p. 14).

A empatia, a emoção, o afeto devem, sim, fazer parte dos processos pedagógicos, defendia Freinet (1977). Tanto que, em seus famosos projetos de jornais escolares (1974), ele definia os jornais dos seus estudantes como "afetivos". Ao invés de serem publicações impessoais como as dos adultos, lidavam intencionalmente com experiências, emoções, sensações, sentimentos. Da mesma forma, acreditamos que, no ensino de jornalismo, a interação entre o estudante e a fonte, por meio de uma história de vida, somada ao compartilhamento dessa história, convocam o escrevente a iniciar o processo de assumir a responsabilidade pelo que escreve. Tratando do tema, Bazerman aborda o que ocorre numa dimensão mais profunda no processo de aprender a escrever e no exercício dessa prática: "significa aprender a assumir uma presença ousada no mundo e entrar em complexas e sofisticadas relações com os outros [...]. O desenvolvimento dos estudantes como escritores é permeado de questões de identidade, afeto, alegria e de definição do seu lugar no mundo (BAZERMAN, 2007, p. 110).

Muitos pesquisadores acreditam que o jornalismo tenha muito a colaborar em processos de ensino-aprendizagem da escrita, por meio dos seus procedimentos, premissas e gêneros ${ }^{1}$. Isto porque o caminho que leva à escrita passa pela fala. É o que indicam pesquisas antigas e contemporâneas sobre linguagem. A colaboração que a fala pode dar no aprendizado da escrita vem do fato de que uma nova habilidade se desenvolve a partir de uma antiga (KATO, 1986). Assim, o processo de aquisição do novo parte do que já é conhecido. Em todas as culturas, o oral é a base, o ponto de partida. A fala é uma capacidade inata. Por isso, em seus momentos iniciais, a escrita sempre imita a fala. E depois é a fala que imita a escrita (LURIA, 1986). Nos últimos anos, pesquisadores de diversas áreas têm buscado superar a visão dicotômica da relação entre fala e escrita. Ao invés de amplificar as diferenças,

1 Para citar apenas alguns exemplos: Freinet (1974) revolucionou o ensino do francês como língua materna criando jornais com seus jovens alunos. A imprensa escolar era parte fundamental da sua pedagogia, que vem sendo replicada por milhares de educadores no Brasil e outros países. Os Parâmetros Curriculares Nacionais (BRASIL, 1998) para o ensino de língua portuguesa no ensino fundamental indicam que gêneros textuais de imprensa devem ser exercitados como forma de desenvolvimento da leitura e escrita. Por isso, professores e pesquisadores da área de Letras muitas vezes trabalham com gêneros jornalísticos, como na pesquisa "A produção escolar do gênero entrevista: a retextualização como prática da escrita" (NETO; SANTOS, 2017). 
reconhecer e valorizar as semelhanças, as interseções, o que pode ser também um caminho para facilitar o desenvolvimento da escrita. O que assume importância ainda maior em países como o Brasil, que é profundamente oral. Isto é, as iniciativas que lidam com o desenvolvimento da escrita precisam encontrar formas de estabelecer diálogos entre a linguagem oral e a escrita. E também porque, em tempos de comunicação digital, uma nova escrita vem sendo desenvolvida entre os mais jovens, em profundo diálogo com a oralidade, como constataram Amanda de Oliveira e Alexandre Barbalho, estudando a comunicação entre jovens pelo WhatsApp: “[...] percebemos o quanto as marcas da comunicação oral estiveram presentes. Palavras eram escritas especialmente do modo como eles falavam. As construções frasais nas mensagens de texto correspondiam mais à forma oral que à representação escrita" (OLIVEIRA; BARBALHO, 2017, p. 90).

A colaboração do jornalismo a esse "diálogo entre linguagem oral e escrita" vem de dois fatores. O primeiro é a importância dos gêneros orais no jornalismo (entrevista para rádio, entrevista para TV, reportagem para rádio, reportagem para TV, etc.) (MORIN, 1973). O que faz do jornalismo um campo com vasta expertise em relação à produção e disseminação de gêneros orais. O segundo fator é que, mesmo os gêneros escritos frequentemente estão amparados em dados orais, coletados por meio de entrevistas.

A pertinência da inclusão dos gêneros orais em ambientes educacionais não é uma novidade. Afinal, muitos já compreendem como papel da escola a "missão de ensinar os alunos a escrever, ler e a falar", como descrevem Schneuwly e Dolz (2004). Em diferentes artigos, os dois pesquisadores se dedicam ao tema dos gêneros orais e indicam como convertê-los em objetos de ensino, propondo sequências e modelos didáticos para o ensino de gêneros como exposição oral, debate e entrevista radiofônica. No Brasil, os PCNs para o ensino da língua portuguesa, de 1998, fazem diversas referências ao tema, propondo como metas do trabalho com estudantes o desenvolvimento da "compreensão oral e escrita", da "produção oral e escrita" ou ainda mais enfaticamente: "cabe à escola ensinar o aluno a utilizar a linguagem oral no planejamento e realização de apresentações públicas: realização de entrevistas, debates, seminários, apresentações teatrais etc.” (BRASIL, 1998, p. 25).

Os PCNs indicam nominalmente alguns gêneros que consideram "privilegiados" para “escuta e leitura de textos". Assim como "sugerem" alguns para a "prática de produção de textos orais e escritos". Entre os gêneros orais sugeridos para ampliação de repertório aparecem os "de imprensa", como comentário radiofônico, entrevista, debate e depoimento e "publicidade: propaganda. O mesmo ocorre entre os gêneros jornalísticos orais listados como 
recomendáveis para a prática de produção de textos: notícia, entrevista, debate e depoimento. Alguns gêneros jornalísticos escritos também fazem parte do repertório das atividades de leitura e escrita.

No ambiente do ensino de jornalismo, há consenso em relação à necessidade de praticar diversos gêneros orais e escritos como forma de habilitar os estudantes ao exercício profissional (BRASIL, 2013). Também há certa clareza sobre quais seriam esses gêneros, tipos de textos e como eles devem ser produzidos. Entretanto, pouco se sabe do ponto de vista do ensino-aprendizagem desses gêneros. E, especialmente, o que ocorre durante a retextualização, a passagem do oral (fala do entrevistado) para o escrito (texto jornalístico). Quais os desafios que o estudante enfrenta? Quais as potencialidades do trabalho simultâneo com o oral e o escrito? Que aspectos podem intervir mais decisivamente nessa passagem?

A escolha do gênero perfil nesse estudo parte também das suas características facilitadoras. Trata-se de um gênero com formato bastante flexível. Ao contrário de outros gêneros jornalísticos, que solicitam a conjugação de fontes variadas, a escrita do perfil pode se apoiar exclusivamente (se esta for a melhor opção para o estudante) em uma única entrevista: a fala do entrevistado-perfilado. E esta fala já possui uma ordem, uma organização dos tópicos/temas. Se a opção do escrevente for reordenar os tópicos tratados na entrevista, o perfil também colabora. Pois o fato do seu conteúdo tratar de um assunto que nos é familiar, facilita na reordenação dos tópicos. Definido por alguns como um gênero de "caráter narrativo", de "memorização das ações humanas" ou "interpretativo" (MARQUES DE MELO, 2009), o fato é que o perfil tem como foco contar uma história de vida. E, assim, aproxima-se de um gigantesco conjunto de gêneros, de uma fonte inesgotável de referências, que podem apoiar o estudante na sua escrita.

O objetivo aqui será observar em que medida e de que modo o oral participa da produção do escrito. Por isso buscamos uma categoria de análise que lida com uma dimensão ampla e fundamental para entender a realização da linguagem: o tópico, aquilo sobre o que se fala. $\mathrm{O}$ aspecto a ser investigado diz respeito à organização tópica. Tentaremos 1- observar a organização tópica da entrevista que o estudante produziu a partir da interação oral e 2compará-la com a organização tópica do texto final escrito por ele. A intenção é identificar se a sequência dos segmentos tópicos se repete ou não, se e quando eles tendem a respeitar a sequência da fala do entrevistado. E, quando ocorre a reordenação tópica, investigar que aspectos podem participar desse processo. As perguntas que tentaremos responder nessa investigação são: sendo a escrita jornalística um processo, em boa medida, de retextualização 
da fala, que operações de retextualização (reformulações, eliminações, acréscimos, manutenções) dos segmentos tópicos da fala ocorreram na produção da escrita? E, ainda, que opções didáticas podem estar sintonia com as soluções exploradas pelos estudantes em função da maturidade da sua escrita?

Mas por que nos preocuparmos com aspectos tão íntimos da produção textual? Por que buscar caminhos para entender e facilitar a escrita de universitários? Porque o ambiente do ensino superior de jornalismo também é um contexto de aprendizado da escrita e, às vezes, também de aprendizado da norma-padrão da língua. A afirmação anterior, que pode parecer óbvia para alguns, certamente soa estranha para muitos. Alain Coulon (2008), no contexto francês, reforça que entre os fatores que definem o fracasso ou êxito dos estudantes na afiliação à vida universitária, está a afiliação intelecutal, o aprendizado do vocabulário, regras da escrita acadêmica, capacidade de leitura, desenvolvimento da concentração. Marcela Mello destaca, entretanto, que, apesar da importância do tema, são poucos os estudos entre nós sobre o ensino e a aprendizagem da escrita acadêmica e faz afirmações contundentes que se aplicam ao ensino superior em geral e também ao ensino do jornalismo:

É possível verificar que na prática a maioria dos docentes não consegue perceber que grande parte das dificuldades estão relacionadas ao fato de que a aprendizagem não está concluída quando os discentes ingressam na universidade; que a aprendizagem da escrita é contínua; e que para cada prática de letramento se faz necessário determinados conhecimentos textuais e sociais. E, por não terem consciência sobre essas questões, além de responsabilizam os professores do Ensino Médio pelas deficiências dos alunos, os docentes universitários não se empenham em auxiliar os alunos no processo de produção e compreensão da escrita acadêmica (MELLO, 2017, p. 6).

O ambiente de ensino de jornalismo é heterogêneo, incluindo-se aí o grau de letramento dos estudantes. Uma situação em sintonia com o contexto nacional. O Indicador de Alfabetismo Funcional (INAF) 2011-2012 indica o seguinte quadro da leitura, escrita e domínio de operações matemáticas entre a população brasileira de 15 a 64 anos: 6\% de analfabetos, $21 \%$ com domínio rudimentar, $47 \%$ com domínio básico e apenas $26 \%$ com domínio pleno. Portanto, não é raro encontrar estudantes que não têm domínio pleno da leitura e escrita. Em alguns casos, filhos de pessoas com poucos anos de escolarização ou até analfabetos. Estudantes que tiveram intenso convívio com pessoas que não dominam a normapadrão da língua, o que em muitos casos repercute no domínio da norma-padrão que eles 
próprios apresentam. Uma situação que complexifica a prática docente e exige maior repertório de informações para a tomada de decisões didáticas apropriadas.

Esta investigação parte da constatação de que é muito difícil tocar o campo da aprendizagem, de que existem poucos e limitados recursos para abordar como ela se dá. É o que afirmam pesquisadores da área de educação. O que se pode observar são reações e produções dos estudantes, em função dos recursos didáticos e da interação. E, nessas reações e produções, buscar pistas sobre a apropriação dos objetos de ensino por parte dos estudantes, que permitam reelaborar o trabalho docente. Por isso a escolha foi lidar com um corpus formado pela produção (oral e escrita) de estudantes de jornalismo.

\section{DADOS E CATEGORIAS DE ANÁLISE}

Os dados aqui analisados foram coletados entre os participantes de oficinas de texto centradas no gênero perfil ministradas na Escola de Comunicações e Artes da Universidade de São Paulo. Todos os participantes eram estudantes de jornalismo (80\%) e comunicação, vinculados a 11 instituições públicas e privadas do estado de São Paulo. Para a análise, foi selecionada a produção de 15 estudantes. O corpus inclui - para cada participante - dois momentos da elaboração do gênero perfil: o registro da interação oral (entrevista gravada) e o texto escrito (perfil). As análises que serão feitas aqui observam a transcrição das entrevistas (feita por mim) e os textos produzidos pelos estudantes.

Para muitos escreventes-alunos, a definição de uma organização para o texto aparenta ser um dos maiores desafios relacionados à escrita. Por isso o nosso interesse em observar como se dá a relação dialógica entre a fala (entrevista) e a escrita (perfil), na busca das potencialidades dessa interação entre gêneros para a aquisição da escrita. Especialmente para a definição dos tópicos a serem tratados no texto. É possível que existam vários modos de dialogia entre a palavra alheia (do entrevistado) e a palavra própria (do escrevente-aluno). Mas seriam esses modos compatíveis com diferentes momentos de letramento ou poderiam ser explorados em todos os momentos, com diferentes profundidades? E o que a opção, na escrita, por organizações tópicas mais ou menos atreladas à organização tópica da fala do entrevistado pode nos indicar sobre as diferentes soluções experimentadas pelos estudantes?

A realização dessa investigação envolveu algumas etapas. A primeira iniciativa foi identificar os segmentos tópicos que se repetiam nos dois materiais. Em seguida, como a entrevista foi a atividade geradora de conteúdo para criação do texto escrito, ela foi tomada 
como base para a demarcação da organização tópica, por meio de uma numeração desses segmentos tópicos. Essa marcação foi feita com colchetes e números, no início e final do segmento. E então essa mesma numeração foi aplicada aos segmentos tópicos do perfil, clarificando o que se manteve e o que se modificou em relação à organização tópica da entrevista. Isto é, se a numeração também seguiu uma ordem crescente ou se ela era parcial ou completamente independente da ordem em que os segmentos apareceram na entrevista. O que pode significar a intenção de realizar uma reorganização argumentativa.

A conceituação de "tópico discursivo" passou por reformulações. Entre os pesquisadores do Projeto de Gramática do Português Falado (PGPF), segundo Clélia Jubran, essa categoria analítica abstrata foi inicialmente pensada como "fragmento textual caracterizado pela centração em um determinado tema" (JUBRAN, 2006, p. 33). Reconhecendo a fluidez de uma palavra como "tema" e as limitações da ideia de "fragmento textual", o conceito de tópico foi depois ampliado para "uma unidade discursiva, não restrita ao turno, cujas particularidades estariam assentadas na integração de enunciados em um conjunto relevante de referentes e cujos limites seriam dados pela proeminência desse conjunto em determinado ponto do texto". Em termos mais diretos, Pinheiro afirma que o tópico "serve para descrever o conteúdo sobre o qual se fala/escreve e sinaliza a perspectiva focalizada" (PINHEIRO, 2006, p. 44).

Para efeito de análise, a categoria proposta é a de segmento tópico, que deriva da ideia de tópico discursivo. Para os pesquisadores, enquanto o tópico discursivo seria uma categoria abstrata, o segmento seria uma unidade concreta de análise, localizável no texto: "a sequência textual que preenche as propriedades dessa categoria. [...] O segmento tópico, em outras palavras, constitui cada conjunto de enunciados tematicamente centrados" (PINHEIRO, 2006, p. 46). A noção de tópico, com suas propriedades, serviria assim de base para a operação de "recortar segmentos textuais e descrever a organização tópica de um texto" (JUBRAN, 2006, p. 34). Existem ainda categorias mais abrangentes - subtópicos, quadros tópicos, supertópicos - cada uma delas agrupando elementos do conjunto hierárquico inferior.

Buscamos um modo próprio de aproximação da categoria segmento tópico, adaptado aos interesses da nossa investigação. A ideia de localizar segmentos pareceu muito oportuna como forma de recortar pequenos trechos das transcrições e dos perfis, para poder perceber como os textos foram construídos. Isto é, como forma de localizar que determinado segmento do perfil foi originado de determinado segmento da entrevista. A meta, portanto, foi observar 
como ocorreu o trânsito da entrevista para o perfil. Por isso não pareceu haver necessidade de nomear cada segmento tópico ou de tentar inseri-los em quadros tópicos ou supertópicos.

Após a identificação e demarcação dos segmentos tópicos, o próximo esforço empreendido foi o de identificar e analisar, na construção do perfil, os momentos de manutenção da organização tópica da fala e os de reordenação. Reordenação tópica é um dos aspectos textuais-discursivos que podem ser observados em atividades de retextualização. A ideia aparece em textos de Luiz Marcuschi entre as "atividades de reformulação", que envolveriam também operações como "acréscimo" e "substituição". Marcuschi propõe esta e outras categorias como forma de analisar textos orais (gravados) que foram convertidos em textos escritos. Como já foi dito anteriormente, consideramos que a maioria dos gêneros jornalísticos, sempre que parte da língua falada para a construção do texto escrito, envolve, "em certa medida", atividades de retextualização fala-escrita. Em seu livro "Da fala para a escrita", Marcuschi estuda justamente a retextualização: "Serão identificadas as operações mais comuns realizadas na passagem do texto falado para o texto escrito. Esta passagem ou transformação é uma das formas de realizar o que denomino retextualização" (MARCUSCHI, 2007, p. 46).

Para amparar a análise das retextualizações, Marcuschi propõe um "modelo das operações textuais-discursivas na passagem do texto oral para o texto escrito", composto por nove operações, divididas entre "atividades de idealização" e "atividades de reformulação". O autor acredita que o seu modelo pode servir como um "aferidor da maturidade linguística do retextualizador quanto à consciência das diferenças da relação fala-escrita" (Ibid., p. 76). Como ele mesmo indica, a retextualização é um processo que envolve operações complexas, que "evidenciam uma série de aspectos nem sempre bem-compreendidos da relação oralidade-escrita" (Ibid., p. 76). Ainda que Marcuschi se detenha em retextualizações que buscam ser transcrições fiéis da fala, o que não é o caso do perfil, acreditamos que algumas das operações identificadas por ele também podem ser aplicadas aqui.

A $8^{a}$ operação citada por Marcuschi é a que nos interessa mais de perto. É a de "reordenação tópica do texto e reorganização da sequência argumentativa" (Ibid., p. 75). A observação preliminar de materiais produzidos por estudantes de jornalismo (MARIANO, 2013), já indicava, nos casos de menor maturidade linguística, a tendência de reproduzir, no texto escrito, a sequência das perguntas e respostas que ocorreu durante a entrevista. Já os graus mais acentuados de reordenação dos segmentos tópicos e reorganização da sequência argumentativa, assim como Marcuschi percebeu, parecem estar entre as operações 
normalmente empreendidas por escreventes mais experientes: "esta operação exige alto domínio da escrita e se dá em especial em textos mais complexos em que o aspecto argumentativo predomina ou em diálogos para os quais se sugere uma retextualização mais global sem atenção para detalhes informacionais [..]” (MARCUSCHI, 2007, p. 86).

A $9^{a}$ operação é a de condensação, que não é praticada por todos os escreventes. Tratase de um "agrupamento de argumentos condensando ideias" (Ibid., p. 75). Um exemplo de condensação seria a construção de um período no qual o escrevente reúne ideias que estão espalhadas em momentos distintos da entrevista para sustentar uma tese. Esta operação, que já indica maior autonomia do escrevente, evoca um outro movimento, menos relacionado à retextualização, mas igualmente importante: a interpretação. A interpretação não está totalmente dissociada da retextualização por conta da "compreensão". Como diz Marcuschi, "é necessário considerar que há uma atividade onipresente na atividade de transcrição, que é a compreensão. Sempre transcrevemos uma dada compreensão que temos do texto oral" (Ibid., p. 51). Essa compreensão certamente é influenciada por tudo o que acontece durante a interação oral entre entrevistador e entrevistado. As informações que chegam pelo olhar, silêncios, pigarros, entonações, sorrisos, lágrimas, gestos, posturas, etc. E também é influenciada pelas crenças do entrevistador, pois, em boa medida, entendemos aquilo que queremos ou conseguimos entender.

Os textos jornalísticos são justamente uma alternância entre comentários interpretativos (baseados nos dados coletados e entrevistas) e as citações dos entrevistados (de forma indireta ou direta). Observar nos perfis se e como eles aparecem, possivelmente pode nos dar informações sobre a maturidade da escrita. E, quando se dispõe da entrevistada gravada, é possível também localizar equívocos nessas inferências. Ou seja, evidenciar momentos em que as interpretações não parecem estar baseadas na entrevista. E até considerar em que medida a interação com o professor pode ter influenciado essas "incoerências".

\subsection{Reordenação tópica: quando e por quê}

A análise dos dados constatou que há uma tendência de que a entrevista oral participe da produção do perfil escrito de diferentes modos, em função da maturidade do estudante como escrevente. Em alguns textos, a organização tópica da entrevista foi seguida mais de perto. Ou seja, foi importante para ajudá-los a definir uma sequência de aparição para os segmentos. Nestes mesmos textos - não em todos, mas na maioria -, há influência de recursos 
coesivos da fala, hesitação no uso da pontuação, na realização de inferências baseadas nas informações disponíveis, na elaboração de descrições, tópicos frasais e uso do discurso direto. Portanto, trata-se de uma escrita mais próxima dos recursos da fala. Abaixo um exemplo de texto que mantém grande fidelidade à organização tópica da entrevista. Pela numeração, é possível perceber que os segmentos tópicos foram mantidos em ordem muito próxima da aparição na entrevista oral.

\section{O NOVO}

ALUNA: [1 NOME DA PERFILADA,1][219 ANOS 2] [3 MORA NO BAIRRO DO AEROPORTO SÃO PAULO 3] É [4 ALUNA DO 3o SEMESTRE DE JORNALISMO (INSTITUIÇÃO DE ENSINO SUPERIOR).4][5Veio da escola particular 5] [6 XXX ,6] [8passou na 1o vez. 8]

Sonho

[9 Pensou por muito tempo em fazer musica 9] [7 por tocar flauta,7][9pensava entrar na faculdade de musica 9] mas [11 mudou de idéia no meio do ano,do 30 ano do ensino médio 11] foi [12b e 12 uma mudança grande um choque $12 \mathrm{~b}$ e 12] para todos devido [10 e 10b vir de uma família de músicos ( pai,mãe,irmão ) 10 e 10b] e tambem por não ter se preparado a mais tempo pois [13 se dedicava mais na pratica da musica 13] em si,[15porém conseguiu 15] com sucesso [14 com muita dedicação 14] claro [18 a diferença é muito grande do colégio para o acadêmico são muitos textos 18] [16 mas está amando,16]declara.

À medida em que os estudantes vão ganhando maior intimidade com os recursos da escrita, vai se intensificando a utilização das estratégias citadas acima e também vão surgindo novos planejamentos para os textos, que intensificam a reorganização dos segmentos tópicos. Em alguns momentos, esse planejamento é ainda o esboço de um fio condutor. Em outros, o estudante consegue manter o foco ao longo do texto.

[9 Ele é de XXXX, 9] corinthiano e [3 futuro jornalista, 3] ao que tudo indica. [1 NOME DO PERFILADO 1] [2 tem 20 anos 2] e [4 e 4b sempre gostou de ler e escrever, 4 e 4b] mas [7 um dia antes do fim da inscrição na INSTITUIÇÃO DE ENSINO SUPERIOR, ele ainda estava na dúvida 7] [8 e 5 entre prestar Jornalismo ou seguir a carreira do pai, Engenharia Civil, 8 e 5] [6um caminho que para ele poderia ser mais fácil. 6] Depois de uma conversa com o pai, venceu a vontade do filho.

[10 NOME DO PERFILADO já viajou pelo Brasil inteiro, 10] mas [11 praticamente nunca tinha vindo para São Paulo. 11] [12 e 12b Somente em 2008 é que veio pela primeira vez a cidade com o primo 12 e $12 \mathrm{~b}$ ] e [13 com o sucesso no Vestibular, NOME DO PERFILADO vem definitivamente para São Paulo. 13] 
No caso dos estudantes com maior fluência na escrita, a reorganização dos segmentos tópicos da entrevista passa a ser predominante, ao invés da manutenção da mesma organização. Assim como predomina, na maioria dos casos, a realização de um planejamento mais global que local. A entrevista contribuiu mais como atividade de interação face a face, fornecendo dados para a elaboração de descrições, comentários e para a inclusão de palavras do entrevistado, incorporadas aos textos de diversos modos.

\section{NOME DO PERFILADO - 20 anos}

[4 Um ano de cursinho pré-vestibular foi o tempo necessário 4] de sua contagem regressiva. Com o relógio acelerado que todos carregam aos dezoitos anos, NOME DO PERFILADO estava determinada a partir. [10 e 9 Para não haver surpresa, prestou em pedagogia, letras e jornalismo. 10 e 9] [2 E foi da comunicação, na INSTITUIÇÃO DE ENSINO SUPERIOR, de onde veio a convocação 2] imediata.

Nem todas as casas passam por esse rito de passagem, mas o lar dos MMMM, viveu a experiência de muitos outros. [13 e 6 O filho mais velho partir de casa em busca de primeiro vôo solo. 13 e 6]

NOME DO PERFILADO, assim como VVVV de Luiz Gonzaga, leva a letra WWWW em seu nome. [8 "Eu já estava a fim de sair da minha cidade e viver essa experiência”. 8]

A nossa investigação constatou a seguinte tendência: quanto menor a maturidade na escrita, maior a fidelidade à organização tópica da entrevista e quanto maior a maturidade, maior frequência de planejamentos globais, que levam a reordenações tópicas. Portanto, a organização tópica da fala, em geral, desempenhou papel mais relevante entre os escreventes com menor domínio dos recursos e estratégias próprias da escrita. Enquanto os estudantes com maior domínio dessas estratégias utilizam a entrevista mais como uma forma de interação que permite aquisição de conhecimento.

Isto não significa, necessariamente, que o escrevente menos experiente seja incapaz de criar uma outra organização tópica, em função de um planejamento escolhido por ele ou proposto pelo professor. A organização tópica da fala é um planejamento que já está pronto. Para se distanciar dele, o estudante precisará construir sozinho um outro planejamento, que hierarquiza os segmentos tópicos de um outro modo, atendendo a outros critérios. Portanto, ele precisará definir para si mesmo que plano é esse, que critérios e, principalmente, lembrar de segui-los enquanto produz o texto. Em alguns casos, o estudante parece realizar esse planejamento, mas perdê-lo de vista, o que pode ocorrer pelo fato de que utilizar recursos 
coesivos da escrita, retomar os tópicos, lidar com o vocabulário do escrevente, entre outras operações, já signifiquem grande esforço de memória e raciocínio.

Assim, realizar todas essas operações e também lidar com um planejamento pode significar uma sobreposição de demandas com elevado grau de dificuldade. Provavelmente por isso, em muitos momentos, os escreventes preferiram não colocar em prática um planejamento que envolvesse reordenar os tópicos e não fizeram citações em discurso direto. Ou então realizaram essas tarefas insatisfatoriamente. Portanto, o que se identifica é que a manutenção da organização tópica da fala parece ser um auxílio na realização de uma tarefa que já envolve muitos desafios.

Quando a escrita está mais madura e fluente, os textos ganham maior autonomia em relação às entrevistas. O que estamos chamando aqui de escrevente maduro e fluente é aquele que consegue escrever mais e utilizar mais frequentemente pontuação, vocabulário e recursos coesivos próprios da escrita, além de fazer citações em discurso direto e respeitar as ideias do entrevistado. Vão se tornando mais frequentes também as intervenções mais pessoais dos escreventes: interpretações, observações e outros acréscimos informacionais, por meio, por exemplo, de comparações.

Entre as operações de retextualização que envolvem manutenções, os escreventes menos experientes praticam principalmente a repetição da organização tópica, enquanto os mais experientes repetem o vocabulário e construções dos entrevistados. A organização tópica da fala participa da elaboração dos textos dos escreventes menos experientes de forma expressiva, mas de diferentes modos. Essas diferenças se relacionam tanto com o escrevente e seu estágio de letramento, quanto com a trajetória de cada texto. Pois um mesmo escrevente, em circunstâncias distintas, ampara-se na fala de modos distintos. Como tendência geral, percebe-se uma fidelidade aos segmentos da entrevista, ao que foi dito pelo entrevistado. Isto é, sem acréscimos baseados em interpretações, observações, etc. Já entre os escreventes mais experientes, a operação que ganha expressividade é a manutenção do "modo de dizer" do entrevistado. Isto aparece principalmente em momentos de citação do discurso direto, mas também em outras formas de citação: de palavras e expressões, entre aspas, e de palavras sem aspas que são incorporadas ao texto. As citações de frases ditas na entrevista aparecem com maior frequência e são, em geral, fiéis às palavras do entrevistado, com ligeiras edições. Aparentemente, trata-se de um emprego mais consciente e intencional das próprias palavras e palavras alheias. 
As eliminações sempre estão presentes na produção de textos jornalísticos, na seleção de segmentos e trechos dos segmentos, pois a produção de uma reportagem nunca incorpora toda a informação de uma entrevista. Entre os escreventes menos experientes, os cortes mais expressivos, em geral, eliminaram segmentos ligados a questões polêmicas, vida pessoal e cotidiano dos entrevistados. Os temas polêmicos foram evitados provavelmente por cautela ou dúvida sobre abordagem, já os outros foram possivelmente considerados "secundários". Entre os escreventes mais experientes foram eliminados também segmentos que ajudariam a entender a vida do entrevistado e seus interesses. Como isso ocorreu em textos que utilizam mais nitidamente um fio condutor, que demonstram um planejamento mais global, o critério que guiou essas eliminações pode ter sido a relevância do segmento para o foco escolhido. Isto é, há um planejamento para o texto que leva à exclusão de segmentos que não são relevantes para a proposta argumentativa.

Várias dessas mudanças de ênfase no uso das operações de retextualização parecem estar relacionadas a um progressivo incremento do planejamento global para os textos, à medida que o escrevente torna-se mais maduro. Planejamento expresso principalmente na tentativa de definir e manter um foco ao longo do texto. Quando os escreventes são menos experientes, ou não há um planejamento global ou o fio condutor escolhido nem sempre é construído satisfatoriamente, ainda que seja possível perceber o desejo de utilizar esse recurso. Nos textos dos escreventes mais maduros, o planejamento global é mais frequente e perceptível na definição e manutenção de um foco ao longo texto, que influencia desde a organização tópica até as eliminações de segmentos. Esses estudantes demonstram maior autonomia na manipulação das informações e maior consciência no uso das palavras. Assim, conseguem colocar em prática de forma mais eficaz o planejamento para o texto.

Todas essas observações devem ser entendidas sempre como tendências. Isto é, fatores diversos podem conduzir a escrita dos estudantes em outras direções. Aqui, a exceção mais significativa foi o da estudante com escrita madura que produziu textos fiéis à organização tópica da fala. Talvez, neste caso, a imaturidade ou insegurança estivesse relacionada à interação oral por meio da entrevista. Também existem escreventes inexperientes que já desenvolveram razoável habilidade para planejar de forma mais global os seus textos. Cada escrevente é único, assim como a produção de cada texto é singular.

\section{CONSIDERAÇÕES}


Mesmo reconhecendo a limitação das generalizações, as tendências localizadas nos permitem sugerir algumas opções didáticas que parecem ser compatíveis com as soluções exploradas pelos estudantes. Uma dessas opções é a adaptação dos gêneros (transformações, simplificações), para que o grau de dificuldade seja dosado, como reforçam Schneuwly e Dolz (2004). O que pode equivaler, por exemplo, à realização de tarefas, inicialmente, em grupos ou duplas. No caso de gêneros jornalísticos, isso significaria, por exemplo, entrevistas feitas em duplas, trios, grupos, com pessoa conhecida e só depois com desconhecido. Primeiro apenas uma entrevista e só depois conjugar várias entrevistas. Essa situação, que quase poderia ser definida como uma "entrevista simulada", pode ter um papel positivo entre estudantes iniciantes. Existem casos, inclusive entre estudantes muito proficientes, em que o maior desafio está na interação oral. Fazer a entrevista acompanhado por alguns ou ao menos um colega fortalece e protege os envolvidos. A maior contribuição do jornalismo nessas situações estaria então no gênero oral entrevista, que poderia motivar a interação, ajudando a superar a dificuldade e a desenvolver a proficiência comunicativa oral. Fazer entrevistas com desconhecidos seria o desafio seguinte, que estimularia a capacidade de improviso.

Também é identificada a necessidade da atenção à progressão dos gêneros, priorizando os que envolvem dados de apenas um entrevistado ou que tenham formato flexível. Seja em etapas iniciais, seja na produção dos que demonstram menor experiência na escrita. Os gêneros jornalísticos, por dialogarem intensamente com a oralidade, podem ter papel importante no ensino-aprendizagem da escrita. Mas não se pode esquecer que os diferentes gêneros envolvem diferentes graus de complexidade. Por exemplo, em casos de escreventes inexperientes, o perfil, que tem formato flexível, pode colaborar para evitar o excesso de demandas. Isto é, se o escrevente ainda hesita no emprego de estratégias coesivas, pontuação, maiúsculas, divisão de parágrafos, etc., como solicitar tudo isso e também a produção de um lead, escrita em forma de pirâmide invertida e conjugação de dados e citações de diferentes entrevistados? A produção de uma nota, uma entrevista pingue-pongue ou um relato em primeira pessoa também são opções que envolveriam desafios suficientes para a prática da escrita, sem que a tarefa se tornasse inviável. E sem inibir novas explorações, na medida em que seja possível para o estudante a experimentação de outros recursos.

O respeito aos diversos ritmos de produção dos estudantes também pode ser muito relevante, inclusive para permitir a reelaboração do texto pelo próprio escrevente. Assim, em casos de escreventes iniciantes, pode ser útil evitar a escrita de textos médios e longos e disponibilizar prazos maiores, para que a reelaboração participe do processo de escrita de 
forma constante e produtiva. Reelaboração que, inspirando-se nos métodos de Freinet (1976) e nas teorias de Vygotsky (1995), podem incluir momentos coletivos ou ao menos com a colaboração de um colega. O respeito ao ritmo, a prática da releitura e a reelaboração com objetivos pré-definidos também podem ser importantes na tomada de consciência de aspectos, por exemplo, relacionados à coesão. Muitos estudantes precisam de mais tempo que os colegas para, na produção de um texto, conseguir incluir e diversificar os recursos coesivos. A simples releitura do próprio texto com o objetivo de observar este aspecto já poderia ser também uma atividade produtiva, ainda mais se envolver a reescrita, com o objetivo de substituir as palavras excessivamente repetidas. Como explica Angela Kleiman (1989), a leitura com objetivos definidos é muito mais eficiente.

Muitos desafios da coesão surgem relacionados à pontuação. $\mathrm{O}$ estímulo à construção de períodos curtos, em casos de escreventes inexperientes, pode colaborar na diminuição de repetições e lacunas. O estímulo a uma inserção maior de pontos, certamente traria grandes benefícios à escrita desses estudantes. O emprego de conjunções, o estabelecimento de relações entre as ideias (adição, contraste, etc.) e a busca de formas diversificadas de se referir ao perfilado (substantivos, pronomes) são procedimentos desejáveis. Mas os períodos longos aumentam muito o risco das conexões não serem bem feitas, das ideias ficarem truncadas ou da repetição ocorrer exageradamente. Um outro aspecto a favor dos períodos mais curtos é que, além de facilitarem a escrita, tornam a leitura mais eficaz, como afirma Bocchini (1994).

A análise dos dados identificou também algumas habilidades frequentemente ainda em desenvolvimento que merecem uma atenção especial. A alteração das palavras do entrevistado, mesmo em momentos de uso do discurso direto é muito comum. Em alguns casos, parece haver dificuldade em lidar com as palavras alheias ou desatenção em relação a elas. Em outros, a transformação parece estar relacionada a um certo modo de fazer jornalismo. Por isso é possível afirmar que estudantes em todos os estágios de letramento se beneficiariam de atividades que estimulem a consciência das especificidades da fala do outro e o registro fiel dessa fala. E também de discussões sobre as consequências dessa alteração, da fraude que é atribuir a alguém palavras que ela não disse, além da perda dos significados implícitos no vocabulário do entrevistado.

A necessidade de utilizar todos os sentidos na coleta de dados e na escrita frequentemente não está clara para os estudantes. Nem como isso poderia ser feito. A abordagem do tema em aula, com a utilização de exemplos e, principalmente com a prática, costuma ser eficaz como forma de sensibilização ao fato de que objetos, cheiros, sabores, 
posturas, gestos, tons, texturas e muitos outros elementos também carregam significados. Prática significa realizar exercícios que envolvam observar, experimentar, ouvir, sentir e depois produzir textos a partir dessas percepções, que serão compartilhados. Como diz Oswaldo Coimbra (2002), trata-se de uma forma de incluir elementos de comunicação nãoverbal, que trazem informação, beleza e criatividade ao texto.

Um outro aspecto a desenvolver costuma ser a capacidade de realizar um planejamento mais global que local para o texto. Exercícios de leitura e de escrita podem ajudar a desenvolver a percepção da coerência global de um texto. Como atividade de leitura que estimula a decentração, Mary Kato (1986) sugere a comparação entre versões distintas de uma mesma história (ouvida e lida), com o objetivo de localizar diferenças. E para a escrita ela sugere a produção de um texto sobre relato ouvido, modificando a perspectiva (terceira pessoa). A escrita de um texto num formato previamente definido, como o piramidal, que implica em modificar a organização tópica, envolve um grau de dificuldade maior. Seria preciso, portanto, avançar aos poucos até chegar a esse ponto. $\mathrm{O}$ estímulo à produção de apontamentos, anotações e breves roteiros que planejam a escrita pode ser também um recurso útil.

A existência de atividades desafiadores no processo de ensino-aprendizagem é salutar e necessária, desde que sejam também disponibilizados os meios de torná-las factíveis. Segundo Vygotsky (1991), o aprendizado deve caminhar a frente do desenvolvimento. Ou seja, é importante que as atividades lancem desafios, envolvam habilidades ainda em amadurecimento. Pois o envolvimento na execução dessas atividades leva ao desenvolvimento das habilidades em maturação. Mas como essa "execução" seria possível? Por meio da colaboração, da parceria, da imitação. A imitação participa do aprendizado de forma indispensável, diz Vygotsky (1991). Imitando o que está em nossa zona de desenvolvimento proximal, podemos aprender o que antes não sabíamos. Ou seja, imitando conseguimos avançar, dominar situações e problemas mais complexos do que aqueles que já dominamos.

Tomar a fala como base para a escrita demonstrou ser um recurso produtivo. A entrevista oral forneceu os elementos para a imitação, foi a base para a elaboração do perfil. Segmentos tópicos, ordem de aparição dos segmentos, vocabulário e construções foram - de formas diversas - imitados e, assim, permitiram a todos os escreventes a realização da tarefa. Mesmo no caso dos escreventes que estão em estágios mais iniciais de desenvolvimento da escrita, ocorreu a circulação dialógica (SANTOS, 1999) entre os gêneros entrevista e perfil. 
Os enunciados da fala ecoaram na escrita em diversas tonalidades dialógicas (BAKHTIN, 1986). O fato de conseguir dar vida a um texto é algo muito relevante na perspectiva de pesquisadores como Freinet (1977). Na sua pedagogia, não havia espaço para o fracasso. Pois, alertava ele, todo fracasso tem efeitos físicos e morais que criam bloqueios na aprendizagem. Por isso, ele defendia que a função do educador é encontrar meios de auxiliar os estudantes a atingir os objetivos. Estabelecendo degraus que possam ser vencidos. Reforçando barreiras onde ainda seria prematuro aventurar-se. Abrindo frestas para facilitar o deslocamento. Enfim, colaborando para que tudo ocorra sem crises. Por uma sucessão de êxitos.

\section{REFERÊNCIAS}

BAKHTIN, M. Marxismo e filosofia da linguagem. São Paulo: Hucitec, 1986.

BAZERMAN, C. A escrita como desenvolvimento das relações interpessoais. In: gênero e interação social. São Paulo: Cortez, 2007. p. 110-118.

Escrita,

BOCCHINI, Maria Otília. Formação de redatores para a produção de textos acessíveis a leitores pouco proficientes: o caso de Mulher e Saúde, boletim do SOF na luta pela saúde das mulheres. 1994. 244 f. Tese (Doutorado em Ciências da Comunicação) - Escola de Comunicações e Artes, Universidade de São Paulo, São Paulo, 1994.

BRASIL. Conselho Nacional de Educação / Câmara de Educação Superior. PARECER CNE/CES N: 39/2013 e PROJETO DE RESOLUÇÃ̃O que Institui as Diretrizes Curriculares Nacionais para o Curso de Graduação em Jornalismo. Brasília: MEC/CNE, 2013.

BRASIL. Secretaria de Educação Fundamental. Parâmetros curriculares nacionais: terceiro e quarto ciclos do ensino fundamental: língua portuguesa / Secretaria de Educação Fundamental. Brasília: MEC/SEF, 1998.

CERQUEIRA NETO, José Calais; Santos, Adelino Pereira dos. A retextualização como prática de produção de textos no Ensino Fundamental: os resultados de uma experiência. Letras \& Letras, Uberlândia, v. 33, n. 2, p. 108-134, jul./dez. 2017.

COIMBRA, Oswaldo. O texto da reportagem impressa. São Paulo: Ática, 2002.

COULON, Alain. A condição de estudante: a entrada na vida universitária. Salvador: EDUFBA, 2008.

FREINET, C. O Jornal Escolar. Lisboa: Editorial Estampa, 1974.

O Método Natural III - A aprendizagem da escrita. Lisboa: Editorial Estampa, 1977.

O texto livre. Lisboa: Dinalivro, 1976.

JUBRAN, C. Revisitando a noção de tópico discursivo. Cadernos de Estudos Linguísticos / O tópico discursivo, Campinas, v. 48, n. 1, p. 33-41, 2006.

KATO, M. No mundo da escrita: uma perspectiva psicolinguística. São Paulo: Ática, 1986. 
KLEIMAN, Angela. Texto e leitor: aspectos cognitivos da leitura. Campinas, SP: Pontes, 1989.

LURIA, A. R. Principais formas de alocução verbal. Linguagem oral (colóquio e monólogo) e linguagem escrita. In: Alegre: Artes Médicas, 1986. p. 163-172.

MARCUSCHI, L. A. Da fala para a escrita: atividades de retextualização. São Paulo: Cortez, 2007.

Referenciação e progressão tópica: aspectos cognitivos e textuais. Cadernos de Estudos Linguísticos / O tópico discursivo, Campinas, v. 48, n. 1, p. 7-22, 2006.

MARIANO, A. F. de C. Gêneros jornalísticos no ensino-aprendizagem da escrita: da entrevista ao perfil. Revista Fronteiras, São Leopoldo, v. 15, p. 86-95, 2013.

MARQUES DE MELO, J. Gêneros jornalísticos no Brasil: o estado da questão. In: CONGRESSO BRASILEIRO DE CIÊNCIAS DA COMUNICAÇÃO - INTERCOM, 32., 2009, Curitiba. Anais eletrônicos... São Paulo: Intercom, 2009. Disponível em:

<http://www.intercom.org.br/papers/nacionais/2009/resumos/R4-0763-1.pdf >. Acesso em: 21 nov. 2012.

MEDINA, C. Entrevista, o diálogo possível. São Paulo: Ática, 1995.

MELLO, Marcela Tavares. Reflexões sobre as práticas letradas no ensino superior. In: REUNIÃO NACIONAL DA ANPED, 38., 2017, São Luís. Anais eletrônicos... São Luís: UFMA, 2017. p. 01-16. Disponível em: <http://anais.anped.org.br/sites/default/files/arquivos/ trabalho_38anped_2017_GT10_598.pdf>. Acesso em: 30 jan. 2018.

MORIN, E. A entrevista nas ciências sociais no rádio e televisão. In: MOLES, A. et al. Linguagem da cultura de massas: televisão e canção. Petrópolis: Editora Vozes, 1973. p. 115-135.

OLIVEIRA, Amanda Nogueira de; BARBALHO, Alexandre. Entre o WhatsApp e a praça da "família": relato de uma experiência teórico-metodológica. Comunicação \& Educação, São Paulo, ano 22, n. 2, p. 85-94, jul./dez. 2017.

PINHEIRO, C. O tópico discursivo como categoria analítica textual-interativa. Cadernos de Estudos Linguísticos / O tópico discursivo, Campinas, v. 48, n. 1, p. 43-51, 2006.

REZENDE, R. C. O tópico discursivo em questão: considerações teóricas e análise de uma narrativa literária. Cadernos de Estudos Linguísticos / O tópico discursivo, Campinas, v. 48, n. 1, p. 71-84, 2006.

SANTOS, S. N. G. O gesto de recontar histórias: gêneros discursivos e produção escolar escrita. 1999, 204 f. Dissertação (Mestrado em Linguística Aplicada) - Instituto de Estudos da Linguagem, Universidade Estadual de Campinas, Campinas, 1999.

SCHNEUWLY, B. Palavra e ficcionalização: um caminho para o ensino da linguagem oral. In: ROJO, R.; CORDEIRO, G. S. (Orgs.). Gêneros orais e escritos na escola. Campinas / São Paulo: Mercado de Letras, 2004. p. 129-147.

; DOLZ, J. Os gêneros escolares - das práticas de linguagem aos objetos de ensino. In: ROJO, R.; CORDEIRO, G. S. (Orgs.). Gêneros orais e escritos na escola. Campinas / São Paulo: Mercado de Letras, 2004. p. 71-91. 
SODRÉ, M. Técnica de reportagem: notas sobre a narrativa jornalística / Muniz Sodré, Maria Helena Ferrari. São Paulo: Summus, 1986.

VILAS BOAS, S. Perfis: e como escrevê-los. São Paulo: Summus, 2003.

VYGOTSKI, L. S. A formação social da mente. São Paulo: Martins Fontes, 1991.

. Pensamento e linguagem. São Paulo: Martins Fontes, 1995, 135 p.

Possui graduação em Comunicação Social - Jornalismo pela Universidade Federal da Bahia, mestrado em Comunicação e Cultura Contemporâneas pela mesma instituição e doutorado em Ciências da Comunicação pela Universidade de São Paulo. É professora da Universidade Federal de Ouro Preto, da graduação em Jornalismo e do Programa de Pós-graduação em Comunicação e Temporalidades, onde desenvolve pesquisas relacionadas à memória oral.

Esta obra está licenciada sob uma Licença Creative Commons.

Esta obra está licenciada sob uma Licença Creative Commons. 